\title{
A Comparative Analysis of Tooth Size Discrepancy between Male and Female Subjects Presenting with a Class I Malocclusion
}

\author{
Eva Man Yee Leung, ${ }^{1}$ Yanqi Yang ${ }^{D},{ }^{1}$ Balvinder Khambay, ${ }^{2}$ Ricky Wing Kit Wong, \\ Colman McGrath, ${ }^{4}$ and Min Gu (iD) ${ }^{1}$ \\ ${ }^{1}$ Orthodontics, Faculty of Dentistry, The University of Hong Kong, 34 Hospital Road, Hong Kong \\ ${ }^{2}$ College of Medical and Dental Sciences, The School of Dentistry, University of Birmingham, Birmingham, UK \\ ${ }^{3}$ Department of Dentistry and Maxillofacial Surgery Cleft Center (Craniofacial Orthodontics), United Christian Hospital, \\ 130 Hip Wo Street, Kwun Tong, Kowloon, Hong Kong \\ ${ }^{4}$ Dental Public Health, Faculty of Dentistry, The University of Hong Kong, 34 Hospital Road, Hong Kong
}

Correspondence should be addressed to Min Gu; drgumin@hku.hk

Received 5 May 2018; Accepted 2 July 2018; Published 15 July 2018

Academic Editor: Grant McIntyre

Copyright (C) 2018 Eva Man Yee Leung et al. This is an open access article distributed under the Creative Commons Attribution License, which permits unrestricted use, distribution, and reproduction in any medium, provided the original work is properly cited.

\begin{abstract}
Objectives. To evaluate the tooth size discrepancy and Bolton's ratios between male and female subjects with a Class I malocclusion. Materials and Methods. The digital e-models of 100 male and 100 female 12-year-old southern Chinese children with a Class I malocclusion were selected. The mesiodistal widths from permanent first molar to the contralateral side first molar of the upper and lower dentitions were measured. Differences between the tooth size discrepancy, together with the anterior and overall Bolton's ratios between male and female subjects, were assessed using a two-sample $t$-test. A paired $t$-test was used to determine differences between antimetric pairs of teeth within the same arch. Results. Females had statistically significant smaller teeth than males $(P<$ $0.05)$ except the upper left and lower left lateral incisor and lower left and right central incisors. The mean values of anterior Bolton's ratios for males and females were 77.04 and 77.03, respectively $(P>0.05)$, while the mean values of overall Bolton's ratios of male and female are 90.48 and 90.65 , respectively $(P<0.05)$. The clinical significant differences (Cohen's $\mathrm{d}>0.2)$ for contralateral tooth size were shown on the maxillary canines, lateral incisors, and central incisors of males; and mandibular canines and lateral incisors of females. Conclusions. Southern Chinese females presenting with Class I malocclusions have smaller mesiodistal tooth dimensions compared to males. Both males and females presented several tooth size asymmetries. There are no statistical differences in anterior and overall Bolton's ratios between the genders.
\end{abstract}

\section{Introduction}

The maxillary to mandibular tooth size relationship is important to achieve ideal overjet, overbite, and occlusal interdigitation following orthodontic treatment and is often referred to as the "seventh key" to an ideal occlusion [1]. A tooth size discrepancy can affect the final outcome and stability of orthodontic treatment $[2,3]$. Previous studies have shown a correlation between the mesiodistal tooth widths of maxillary and mandibular teeth in Caucasians [4-6]. Ratios for the estimation of tooth size discrepancy have been reported as the "Bolton's standards" [2]. The first ratio, the anterior ratio, is obtained by measuring the summed mesiodistal widths of the mandibular to maxillary anterior teeth, while the second or overall ratio is the summation of mesiodistal widths of all mandibular to maxillary teeth from first molar to first molar.

Previous studies have compared tooth size between males and females of individuals with Class I malocclusions from America, Egypt, and Mexico [7]. The total and anterior Bolton ratios have been reported greater in males than in females, in a British population and in a black, Hispanic, and white population $[8,9]$, while others have reported no differences in anterior or posterior tooth size proportions between males and females in black North American and a Saudi population [10,11].

Besides ethnicity influencing tooth size, studies have reported that tooth size discrepancies may vary among different malocclusion groups. A study based on southern Chinese 
children validated the use of Bolton standards in individuals with a Class I occlusion but not those with Class II or Class III malocclusions [12]. A recent study confirmed a highest percentage of clinically significant tooth size discrepancy in Class II and Class III surgical cases [13]. Interestingly another Chinese population study showed there was a higher frequency of tooth size discrepancy in Class III malocclusions compared to other malocclusion types [14].

Differences in dental morphology in the Southern Chinese and Hong Kong population have previously been reported [15]. There was a higher prevalence of hyperdontia (2.6\%), congenitally missing mandibular incisors (5.6\%), dens evaginatus (4.7\%), and double tooth $(0.8 \%)$ than reported in Caucasians. In addition, there was a higher prevalence of semi-shovel shaped maxillary incisors (45.6\%) and protostylid cusps on mandibular molars (37.5\%) in the Southern Chinese and Hong Kong population. Some of these localized dental morphological variations may have an effect on the Bolton ratio. Therefore Bolton's ratios may not be applicable for both genders, across populations or between malocclusions.

This research aimed to compare the tooth size, as well as the Bolton anterior and overall ratios between male and female southern Chinese individuals presenting with a Class I malocclusion. The null hypothesis is that there is no difference in tooth size and Bolton ratio between male and female southern Chinese individuals presenting with a Class I malocclusion.

\section{Materials and Methods}

2.1. Sampling. A sample of orthodontic digital e-models of 609 random 12-year-old southern Chinese children was obtained as a part of data in a cross-sectional oral health survey named "Children of 1997" conducted at the Faculty of Dentistry, the University of Hong Kong. This sample was recruited from 45 secondary schools (accounting for about $10 \%$ of all local secondary schools in Hong Kong) from 18 districts of Hong Kong. From the 609 digital models, 100 males and 100 females were selected as having a Class I malocclusion based on the British Standard Institution incisor relationship and met the following inclusion criteria [16]:

(i) Permanent dentition present (excluding third molars)

(ii) No previous or current active orthodontic treatment

(iii) No impacted teeth

(iv) No hypodontia

(v) No carious teeth, teeth with interproximal restoration, or fractured teeth

(vi) No abnormal tooth morphology

This study was approved by the Institutional Review Board of the University of Hong Kong/Hospital Authority Hong Kong West Cluster (UW 09-453).

2.2. Sample Size Calculation. The estimation of sample size was calculated by running the G*Power 3.17 (Franz Faul,

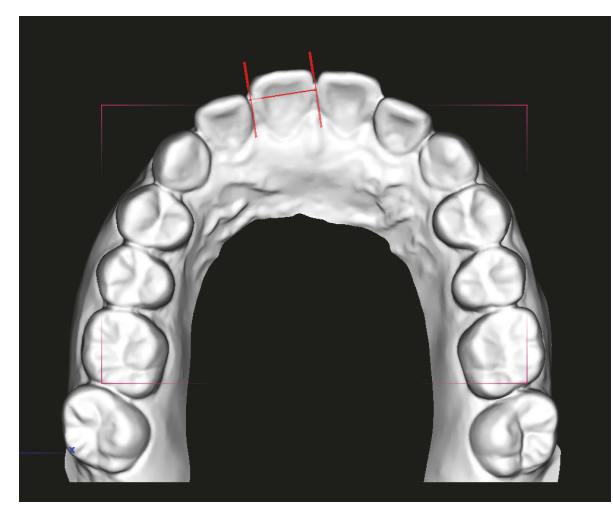

FIGURE 1: Measurement of tooth width using O3DM digital model software.

University Kiel, Germany 2013) software. A sample size of 200 subjects is required in order to detect clinically significant difference based on an Altman nomogram with a power of 0.8 at $P<0.05$; standard deviation and standardized difference are 1.0 and 0.4 , respectively [17].

2.3. Digital Models Measurement. Each patient's e-model was imported and viewed in O3DM digital model software programme (Version 3.2.1, Ortholab 2003-2012, Poland). Definitions of mesiodistal crown width based on criteria of Seipel [18]. The e-models were enlarged and rotated into different angulation to allow more precise identification of the mesial and distal contact points along the occlusal surfaces of each tooth [19]. After calibration with another orthodontist (YY) experienced in e-model measurement, the same operator (EL) measured the mesiodistal width of the teeth from incisors, canines, premolars, and first molars in both maxillary and mandibular arches using the appropriate measurement tool incorporated in the software (Figure 1). Individual tooth mesiodistal tooth width and anterior and overall Bolton's ratios were calculated.

Anterior and overall Bolton's ratios were calculated with the following formula:

\section{Anterior Bolton's ratio}

$$
=\frac{\text { Sum of mandibular 3-3 }}{\text { Sum of maxillary 3-3 }} \times 100
$$

Overall Bolton's ratio

$$
=\frac{\text { Sum of mandibular 6-6 }}{\text { Sum of maxillary 6-6 }} \times 100
$$

2.4. Intraoperator Error. Twenty sets of e-models chosen at random were selected for intraoperator error assessment. The mesiodistal widths of each tooth from first molar to contralateral first molar for upper and lower arches were measured twice with a 2 -week interval by the same observer (EL). The intraclass correlation coefficient (ICC) was 0.90 , indicating that the reliability of these measurements was satisfactory. 
TABLE 1: Comparison of the mean tooth size, the mean anterior, and overall Bolton's ratio between male and female subjects by two-sample $t$-test.

\begin{tabular}{|c|c|c|c|c|c|c|c|c|c|}
\hline \multirow{2}{*}{ Tooth } & \multicolumn{2}{|c|}{ Male } & \multicolumn{2}{|c|}{ Female } & \multirow{2}{*}{ Mean Difference } & \multirow{2}{*}{ SE of Mean Difference } & \multicolumn{2}{|c|}{ 95\% Confidence Interval } & \multirow{2}{*}{$P$ value } \\
\hline & Mean & $\mathrm{SD}$ & Mean & $\mathrm{SD}$ & & & Lower & Upper & \\
\hline \multicolumn{10}{|l|}{ Maxillary } \\
\hline $\mathrm{T} 16$ & 10.7 & 0.6 & 10.3 & 0.5 & 0.4 & 0.08 & 0.25 & 0.56 & $<0.001 *$ \\
\hline $\mathrm{T} 15$ & 7.3 & 0.4 & 7.0 & 0.4 & 0.2 & 0.06 & 0.10 & 0.32 & $<0.001 *$ \\
\hline $\mathrm{T} 14$ & 7.7 & 0.4 & 7.5 & 0.4 & 0.2 & 0.06 & 0.10 & 0.34 & $<0.001 *$ \\
\hline $\mathrm{T} 13$ & 8.4 & 0.5 & 8.0 & 0.5 & 0.4 & 0.07 & 0.26 & 0.53 & $<0.001 *$ \\
\hline $\mathrm{T} 12$ & 7.3 & 0.5 & 7.2 & 0.6 & 0.2 & 0.08 & 0.00 & 0.30 & 0.05 \\
\hline $\mathrm{T} 11$ & 8.7 & 0.5 & 8.5 & 0.5 & 0.2 & 0.07 & 0.08 & 0.36 & $0.003 *$ \\
\hline $\mathrm{T} 21$ & 8.7 & 0.5 & 8.5 & 0.5 & 0.2 & 0.07 & 0.03 & 0.31 & $0.02 *$ \\
\hline $\mathrm{T} 22$ & 7.3 & 0.5 & 7.1 & 0.5 & 0.1 & 0.07 & 0.00 & 0.29 & 0.054 \\
\hline $\mathrm{T} 23$ & 8.3 & 0.5 & 7.9 & 0.5 & 0.3 & 0.06 & 0.22 & 0.47 & $<0.001 *$ \\
\hline $\mathrm{T} 24$ & 7.8 & 0.4 & 7.5 & 0.4 & 0.2 & 0.06 & 0.10 & 0.34 & $<0.001 *$ \\
\hline $\mathrm{T} 25$ & 7.2 & 0.4 & 7.0 & 0.4 & 0.2 & 0.06 & 0.09 & 0.32 & $<0.001 *$ \\
\hline $\mathrm{T} 26$ & 10.7 & 0.5 & 10.3 & 0.5 & 0.4 & 0.08 & 0.25 & 0.56 & $<0.001 *$ \\
\hline \multicolumn{10}{|l|}{ Mandibular } \\
\hline $\mathrm{T} 36$ & 11.4 & 0.5 & 11.0 & 0.6 & 0.4 & 0.08 & 0.25 & 0.55 & $<0.001 *$ \\
\hline T35 & 7.5 & 0.5 & 7.3 & 0.5 & 0.2 & 0.07 & 0.08 & 0.36 & $0.002 *$ \\
\hline $\mathrm{T} 34$ & 7.6 & 0.4 & 7.4 & 0.4 & 0.2 & 0.06 & 0.04 & 0.28 & $0.01 *$ \\
\hline $\mathrm{T} 33$ & 7.2 & 0.4 & 6.9 & 0.4 & 0.3 & 0.06 & 0.21 & 0.44 & $<0.001 *$ \\
\hline $\mathrm{T} 32$ & 6.1 & 0.4 & 6.0 & 0.4 & 0.1 & 0.05 & -0.02 & 0.19 & 0.11 \\
\hline $\mathrm{T} 31$ & 5.5 & 0.4 & 5.4 & 0.4 & 0.1 & 0.05 & -0.03 & 0.17 & 0.157 \\
\hline T41 & 5.5 & 0.4 & 5.4 & 0.4 & 0.1 & 0.05 & -0.01 & 0.19 & 0.073 \\
\hline $\mathrm{T} 42$ & 6.1 & 0.4 & 6.0 & 0.4 & 0.1 & 0.05 & 0.02 & 0.22 & $0.022 *$ \\
\hline $\mathrm{T} 43$ & 7.2 & 0.4 & 6.8 & 0.4 & 0.4 & 0.06 & 0.28 & 0.50 & $<0.001 *$ \\
\hline $\mathrm{T} 44$ & 7.6 & 0.4 & 7.4 & 0.4 & 0.2 & 0.06 & 0.06 & 0.29 & $0.004 *$ \\
\hline $\mathrm{T} 45$ & 7.5 & 0.5 & 7.3 & 0.5 & 0.2 & 0.07 & 0.06 & 0.33 & $0.004 *$ \\
\hline $\mathrm{T} 46$ & 11.4 & 0.6 & 11.0 & 0.6 & 0.4 & 0.08 & 0.24 & 0.55 & $<0.001 *$ \\
\hline Anterior ratio & 77.04 & 1.86 & 77.03 & 1.86 & 0.01 & 0.26 & -0.51 & 0.52 & 0.987 \\
\hline Overall ratio & 90.48 & 1.79 & 90.65 & 1.60 & 0.17 & 0.24 & -0.64 & 0.31 & 0.486 \\
\hline
\end{tabular}

$* P<0.05 ; \mathrm{SD}=$ standard deviation; $\mathrm{SE}=$ standard error.

In our another study [20], digital model measurements have been compared to plaster cast measurements, and the effect sizes (Cohen's d) were generally less than 0.2 , which showed the validity of digital model measurement was also satisfactory.

2.5. Statistics. Following assessment of normal distribution using the Shapiro-Wilk test, a two-sample $t$-test was used to compare the mean of each tooth width and the mean of anterior and overall Bolton's ratio between male and female subjects; a parted $t$-test was used to test the symmetry of tooth size between contralateral teeth. All the statistical analyses were performed using the Statistical Package for Social Science software (IBM SPSS Statistics 20, IBM Corp., USA).

\section{Results}

3.1. Comparison of Tooth Size. Table 1 shows that females had statistically significant $(P<0.05)$ smaller teeth than males except the following teeth: upper left and lower left lateral incisor and lower left and right central incisors. However, the mean differences of all female and male teeth size were less than or equal to $0.2 \mathrm{~mm}$ except the canines and first molars. The 95\% confidence intervals for the mean differences for males and females were greater than $0.5 \mathrm{~mm}$ for all four first molars and $0.4 \mathrm{~mm}$ for all of canines.

3.2. Comparison of Bolton's Ratio. The mean values for the anterior Bolton's ratio of males and females were $77.04 \pm$ 1.86 and $77.03 \pm 1.86$, respectively; this was not statistical significant $(P>0.05)$. When considering the overall Bolton's ratios, the mean values of male and female are $90.48 \pm 1.79$ and $90.65 \pm 1.60$, respectively; again this was not statistically significant $(P>0.05)$.

3.3. Comparison of Contralateral Tooth Size of the Same Gender. Table 2 shows that the maxillary canines, lateral incisors, and central incisors of males as well as the mandibular canines and lateral incisors in the female group showed a Cohen's d value between 0.2 and 0.5. Values below 0.2 indicate that mean differences in mesiodistal width 
TABLE 2: Comparison of antimetric tooth size within the same gender by paired $t$-test.

\begin{tabular}{|c|c|c|c|c|c|c|}
\hline \multirow{2}{*}{ Tooth pair } & \multirow{2}{*}{$\begin{array}{c}\text { Mean } \\
\text { difference }\end{array}$} & \multirow{2}{*}{ SD } & \multicolumn{2}{|c|}{ 95\% Confidence Interval } & \multirow{2}{*}{ Cohen's d Effect size } & \multirow{2}{*}{ Clinical significance } \\
\hline & & & Lower & Upper & & \\
\hline \multicolumn{7}{|l|}{ Male } \\
\hline T16-T26 & 0.01 & 0.34 & -0.06 & 0.07 & 0.01 & $<0.2$ \\
\hline T15-T25 & 0.03 & 0.22 & -0.01 & 0.08 & 0.14 & $<0.2$ \\
\hline T14-T24 & 0.02 & 0.18 & -0.05 & 0.02 & 0.08 & $<0.2$ \\
\hline $\mathrm{T} 13-\mathrm{T} 23$ & 0.10 & 0.26 & 0.05 & 0.15 & 0.39 & $>0.2 *$ \\
\hline $\mathrm{T} 12-\mathrm{T} 22$ & 0.05 & 0.21 & 0.01 & 0.09 & 0.24 & $>0.2 *$ \\
\hline T11-T21 & 0.06 & 0.20 & 0.02 & 0.10 & 0.29 & $>0.2 *$ \\
\hline T36-T46 & 0.00 & 0.26 & -0.05 & 0.06 & 0.01 & $<0.2$ \\
\hline T35-T45 & 0.04 & 0.24 & -0.01 & 0.08 & 0.16 & $<0.2$ \\
\hline T34-T44 & 0.01 & 0.21 & -0.05 & 0.04 & 0.03 & $<0.2$ \\
\hline Т33-T43 & 0.01 & 0.21 & -0.06 & 0.03 & 0.07 & $<0.2$ \\
\hline Т32-T42 & 0.02 & 0.17 & -0.02 & 0.05 & 0.11 & $<0.2$ \\
\hline T31-T41 & 0.01 & 0.17 & -0.03 & 0.04 & 0.04 & $<0.2$ \\
\hline \multicolumn{7}{|l|}{ Female } \\
\hline T16-T26 & 0.00 & 0.23 & -0.04 & 0.05 & 0.01 & $<0.2$ \\
\hline T15-T25 & 0.03 & 0.20 & -0.01 & 0.07 & 0.14 & $<0.2$ \\
\hline T14-T24 & 0.02 & 0.22 & -0.06 & 0.03 & 0.08 & $<0.2$ \\
\hline T13-T23 & 0.05 & 0.27 & -0.01 & 0.10 & 0.18 & $<0.2$ \\
\hline T12-T22 & 0.05 & 0.25 & -0.01 & 0.10 & 0.18 & $<0.2$ \\
\hline T11-T21 & 0.01 & 0.16 & -0.02 & 0.04 & 0.07 & $<0.2$ \\
\hline Т36-Т46 & 0.00 & 0.24 & -0.04 & 0.05 & 0.02 & $<0.2$ \\
\hline Т35-Т45 & 0.01 & 0.27 & -0.04 & 0.06 & 0.03 & $<0.2$ \\
\hline T34-T44 & 0.01 & 0.23 & -0.04 & 0.06 & 0.04 & $<0.2$ \\
\hline T33-T43 & 0.05 & 0.20 & 0.01 & 0.09 & 0.25 & $>0.2 *$ \\
\hline T32-T42 & 0.05 & 0.17 & 0.02 & 0.09 & 0.31 & $>0.2 *$ \\
\hline T31-T41 & 0.03 & 0.15 & 0.00 & 0.06 & 0.19 & $<0.2$ \\
\hline
\end{tabular}

*Cohen's d > 0.2 = clinical significance; $\mathrm{SD}=$ standard deviation.

between the antimetric pair may not be clinically significant [21].

\section{Discussion}

Although diagnostic measurements have traditionally been based on plaster dental casts, with the advancement of $3 \mathrm{D}$ digital imaging technology, e-models are a valid alternative [22]. The accuracy of space analysis evaluation, tooth width measurements, and arch relationships on digital e-models is clinically acceptable and reproducible when compared with traditional plaster study model analysis [23, 24]. Moreover, digital measurement is more rapid and less variable than the manual method with needle-point dividers or Boley gauge (Vernier caliper) $[25,26]$.

Given that tooth size discrepancies may be influenced by malocclusion type and ethnicity, the sample for this study was selected from a homogenous population of Hong Kong individuals with Class I incisor relationships. We found that females had statistically significant $(P<0.05)$ smaller teeth than males with the exception of the upper left and right lateral incisors, lower left lateral incisor, and lower left and right central incisors. This was in agreement with a previous study which reported that southern Chinese males tooth dimension in general was $2.9 \%$ wider in comparison to females in a random sample irrespective of malocclusion [27]. However, the mean differences between female and male tooth size was less than $0.15 \mathrm{~mm}$, implying this was probably not clinically significant. This finding was comparable to Townsend who reported that the mesiodistal dimensions of maxillary first and second premolars showed sexual dimorphism, with the mean male premolar being wider than female [28]. Morrees [19] also reported that permanent canines were on average $6 \%$ larger in males for both mesiodistal and buccolingual dimensions. Interestingly, the distribution of the teeth involved in the various studies was different. One could surmise that generally if males have larger teeth than females, and there is no difference in lower incisors widths, then males could have smaller incisors than expected perhaps linking this to the higher prevalence of congenitally missing mandibular incisors (5.6\%) in the Hong Kong population [29]. The aetiology of these findings requires further investigation.

One of the proposed aetiologies of tooth anomaly is genetic expression. There is evidence to support the relationship of several dental anomalies, including the delayed eruption, tooth size reduction, and abnormal shape of teeth, with the genetic factors [30]. Family studies have shown that both hypodontia and oligodontia are very likely to be inherited as 
an autosomal dominant trait with variable expression, and peg-shaped incisors are associated with agenesis of second premolars [31].

A previous study comparing the tooth size among different malocclusion types found no statistical difference between males and females, of Han Chinese decent (Beijing sample), in any malocclusion group [14]. However, the Class I group was either normal with no malocclusion or presented with bimaxillary protrusion. The anterior and overall Bolton ratios for this group of individuals from Beijing were found to be $81.52 \pm 2.69$ and $93.51 \pm 2.46$ while from the present study they were $77.04 \pm 1.86$ and $90.48 \pm 1.79$, respectively. This would indicate a difference in Bolton ratio between the Northern Chinese (Beijing sample) and Southern Chinese and Hong Kong individuals. The differences may be due to genetic variation between individuals North of the Yangtze River, i.e., individuals from Beijing, and those South of the river, i.e., Hong Kong, as genetically the populations are different [32]. These differences can be further confirmed by a study from Malaysia [33]. In that study, the anterior and overall Bolton ratios for Chinese were $76.55 \pm 2.68$ and 90.93 \pm 1.87 , respectively, which are very close to those in this study. This may be because the origin of the Chinese population in Malaysia is also from Southern China.

The result of this study supports the previous research finding that there is no sexual dimorphism of the anterior and overall Bolton's ratios in Class I occlusion [34].

Upon the consideration of tooth size discrepancy of contralateral incisors, canines, premolars, and molars of the same arch within the same gender, only the maxillary canines, lateral incisors, central incisor in males, and the mandibular canines and lateral incisors of females showed low levels of clinical significance. These are based on the calculation of Cohen's d (mean difference divided by standard deviation) between 0.2 and 0.5 [21].

Clinical application of Bolton's ratios enables orthodontists to plan the ideal aesthetic and functional outcomes of an orthodontic case without using a diagnostic setup. Orthodontists can also use it to assess the need for composite build up or tooth size reduction by interproximal stripping for those patients presenting with clinical significance in tooth size discrepancy $[3,35]$. Because in some teeth the $95 \%$ confidence intervals for differences in mesiodistal between males and females were above $0.5 \mathrm{~mm}$, even though the Bolton ratios were not different between males and females in this sample, individual tooth size and left-right asymmetry should also be taken into account as it was noted in both genders.

\section{Conclusions}

(1) Females had statistically significant smaller teeth than males in southern Chinese except the upper left and lower left lateral incisor and lower left and right central incisors.

(2) The anterior Bolton's ratios of males and females are 77.04 and 77.03, respectively, while the overall Bolton's ratios of male and female are 90.48 and
90.65, respectively. There were no significant gender differences in both ratios.

(3) This study showed evidence that low level of clinical significant differences of the contralateral tooth size of maxillary canines, lateral incisors, and central incisors of southern Chinese male existed. On the other hand, low levels of clinical significant differences of contralateral tooth size of mandibular canines and lateral incisors were found in female.

\section{Data Availability}

The data used to support the findings of this study are available from the corresponding author upon request.

\section{Conflicts of Interest}

This is a declaration that there are no conflicts of interest associated with this research.

\section{References}

[1] R. P. Mclaughlin, Orthodontic management of the dentition with the preadjusted appliance, Mosby, 2001.

[2] W. A. Bolton, Disharmony in tooth-size and its relation to the analysis and treatment of malocclusion, vol. 28, Angle Orthodontist, 1958.

[3] W. A. Bolton, "The clinical application of a tooth-size analysis," American Journal of Orthodontics and Dentofacial Orthopedics, vol. 48, no. 7, pp. 504-529, 1962.

[4] "Asymmetry in tooth size: A factor in the etiology, diagnosis and treatment of malocclusion," American Journal of Orthodontics and Dentofacial Orthopedics, vol. 32, no. 4, pp. 239-240, 1946.

[5] M. M. Tanaka and L. E. Johnston, "The prediction of the size of unerupted canines and premolars in a contemporary orthodontic population.," Journal of the American Dental Association (1939), vol. 88, no. 4, pp. 798-801, 1974.

[6] C. W. Neff, "Tailored occlusion with the anterior coefficient," American Journal of Orthodontics and Dentofacial Orthopedics, vol. 35, no. 4, pp. 309-313, 1949.

[7] S. E. Bishara, J. R. Jakobsen ?, E. M. Abdallah, and A. Fernandez Garcia, "Comparisons of mesiodistal and bnccolingnal crown dimensions of the permanent teeth in three populations from Egypt, Mexico, and the United States," American Journal of Orthodontics and Dentofacial Orthopedics, vol. 96, no. 5, pp. 416-422, 1989.

[8] C. L. B. Lavelle, "Maxillary and mandibular tooth size in different racial groups and in different occlusal categories," American Journal of Orthodontics and Dentofacial Orthopedics, vol. 61, no. 1, pp. 29-37, 1972.

[9] S. S. Smith, P. H. Buschang, and E. Watanabe, "Interarch tooth size relationships of 3 populations: "Does Bolton's analysis apply?", American journal of orthodontics and dentofacial orthopedics : official publication of the American Association of Orthodontists, its constituent societies, and the American Board of Orthodontics, vol. 117, no. 2, pp. 169-174, 2000.

[10] E. R. Richardson and S. K. Malhotra, "Mesiodistal crown dimension of the permanent dentition of American Negroes," American Journal of Orthodontics and Dentofacial Orthopedics, vol. 68, no. 2, pp. 157-164, 1975. 
[11] T. Al-Tamimi and H. A. Hashim, "Bolton tooth-size ratio revisited." World Journal of Orthopedics, vol. 6, no. 3, pp. 289295, 2005.

[12] T. A. Ta, J. Y. K. Ling, and U. Hägg, "Tooth-size discrepancies among different occlusion groups of southern Chinese children," American Journal of Orthodontics and Dentofacial Orthopedics, vol. 120, no. 5, pp. 556-558, 2001.

[13] T. P. McSwiney, D. T. Millett, G. T. McIntyre, M. K. Barry, and M. S. Cronin, "Tooth size discrepancies in Class II division 1 and Class III malocclusion requiring surgical-orthodontic or orthodontic treatment," Journal of Orthodontics, vol. 41, no. 2, pp. 118-123, 2014.

[14] Q. Nie and J. Lin, "Comparison of intermaxillary tooth size discrepancies among different malocclusion groups.", American journal of orthodontics and dentofacial orthopedics : official publication of the American Association of Orthodontists, its constituent societies, and the American Board of Orthodontics, vol. 116, no. 5, pp. 539-544, 1999.

[15] N. M. King, J. S. Tsai, and H. M. Wong, "Morphological and Numerical Characteristics of the Southern Chinese Dentitions. Part I: Traits in the Permanent Dentition," The Open Anthropology Journal, vol. 3, no. 2, pp. 71-84, 2010.

[16] "British Standard Incisor Classification," in Glossary of Dental Terms BS 4492, British Standard Institute London, London, UK, 1983.

[17] A. Petrie, J. S. Bulman, and J. F. Osborn, "Further statistics in dentistry. Part 4: Clinical trials 2," British Dental Journal, vol. 193, no. 10, pp. 557-561, 2002.

[18] "Variations of tooth position, a metric study of variation and adaptation in the deciduous and permanent dentitions," American Journal of Orthodontics and Dentofacial Orthopedics, vol. 34, no. 4, pp. 369-372, 1948.

[19] R. G. Snyder, “The dentition of the growing child: A longitudinal study of dental development between 3 and 18 years of age. By Coenraad F. A. Moorrees. vi + 245 pp. \$5.50. Harvard University Press, Cambridge, 1959," American Journal of Physical Anthropology, vol. 17, no. 3, pp. 249-250, 1959.

[20] C-Y. Leung, Y. Yang, C. Liao et al., "Digital Models as an Alternative to Plaster Casts in Assessment of Orthodontic Treatment Outcomes," The Scientific World Journal, vol. 2018, pp. 1-5, 2018.

[21] J. Cohen, Statistical power analysis for the behavioral sciences, vol. 2 of Hilsdale, Lawrence Earlbaum Associates, 1988.

[22] H. M. El-Zanaty, A. R. El-Beialy, A. M. Abou El-Ezz, K. H. Attia, A. R. El-Bialy, and Y. A. Mostafa, "Three-dimensional dental measurements: An alternative to plaster models," American Journal of Orthodontics and Dentofacial Orthopedics, vol. 137, no. 2, pp. 259-265, 2010.

[23] M. F. Leifert, M. M. Leifert, S. S. Efstratiadis, and T. J. Cangialosi, "Comparison of space analysis evaluations with digital models and plaster dental casts," American Journal of Orthodontics and Dentofacial Orthopedics, vol. 136, no. 1, pp. el1-e14, 2009.

[24] K. Bootvong, Z. Liu, C. McGrath et al., "Virtual model analysis as an alternative approach to plaster model analysis: Reliability and validity," European Journal of Orthodontics, vol. 32, no. 5, pp. 589-595, 2010.

[25] S. A. Othman and N. W. Harradine, "Tooth-size discrepancy and Bolton's ratios: The reproducibility and speed of two methods of measurement," Journal of Orthodontics, vol. 34, no. 4, pp. 234-242, 2007.
[26] M. Dalstra and B. Meisen, "From alginate impressions to digital virtual models: Accuracy and reproducibility," Journal of Orthodontics, vol. 36, no. 1, pp. 36-41, 2009.

[27] J. Y. K. Ling and R. W. K. Wong, “Tanaka-Johnston mixed dentition analysis for southern Chinese in Hong Kong," The Angle Orthodontist, vol. 76, no. 4, pp. 632-636, 2006.

[28] G. C. Townsend, "Intercuspal Distances of Maxillary Pre-molar Teeth in Australian Aboriginals," Journal of Dental Research, vol. 64, no. 3, pp. 443-446, 1985.

[29] N. M. King, J. S. Tsai, and H. M. Wong, "Morphological and Numerical Characteristics of the Southern Chinese Dentitions. Part II: Traits in the Permanent Dentition," The Open Anthropology Journal, vol. 3, no. 2, pp. 71-84, 2010.

[30] C. J. Witkop Jr., "Agenesis of succedaneous teeth: an expression of the homozygous state of the gene for the pegged or missing maxillary lateral incisor trait.," American Journal of Medical Genetics, vol. 26, no. 2, pp. 431-436, 1987.

[31] I. Bailleul-Forestier, M. Molla, A. Verloes, and A. Berdal, "The genetic basis of inherited anomalies of the teeth. Part 1: clinical and molecular aspects of non-syndromic dental disorders," European Journal of Medical Genetics, vol. 51, no. 4, pp. 273-291, 2008.

[32] Y. Ke, B. Su, J. Xiao et al., "Y-chromosome haplotype distribution in Han Chinese populations and modern human origin in East Asians," Science China Life Sciences, vol. 44, no. 3, pp. 225232, 2001.

[33] A. N. A. A. Rahman and S. A. Othman, "Comparison of tooth size discrepancy of three main ethnics in Malaysia with Bolton's ratio," Sains Malaysiana, vol. 41, no. 2, pp. 271-275, 2012.

[34] T-a. Ta, Bolton's ratios among Southern Chinese, Thesis, The University of Hong Kong, China, 1999.

[35] C. Han, J. Dai, H. Qian et al., "The Application of Bolton's Ratios in Orthodontic Treatment Planning for Chinese Patients," The Open Anthropology Journal, vol. 3, no. 2, pp. 65-70, 2010. 


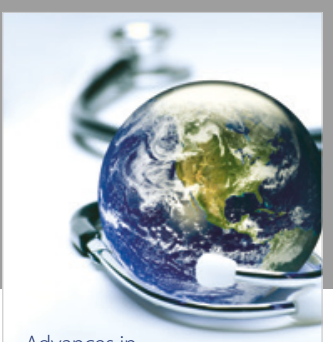

Advances in
Public Health

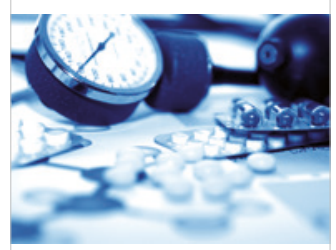

Case Reports in

Medicine

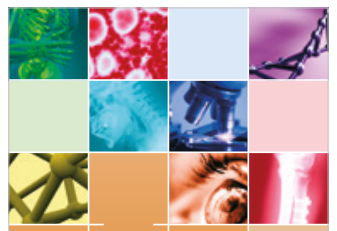

niernational Journal of

Biomaterials
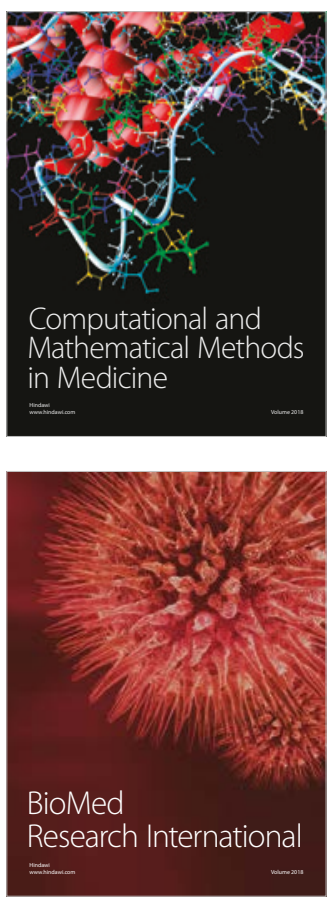

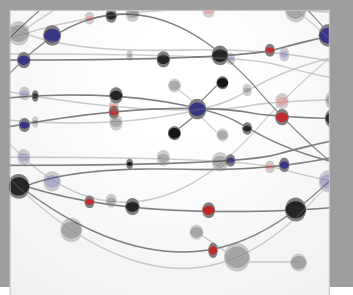

The Scientific World Journal Dentistry

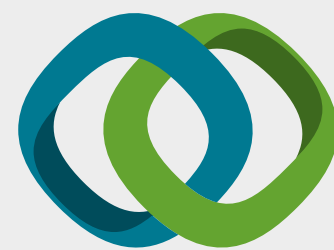

Hindawi

Submit your manuscripts at

www.hindawi.com
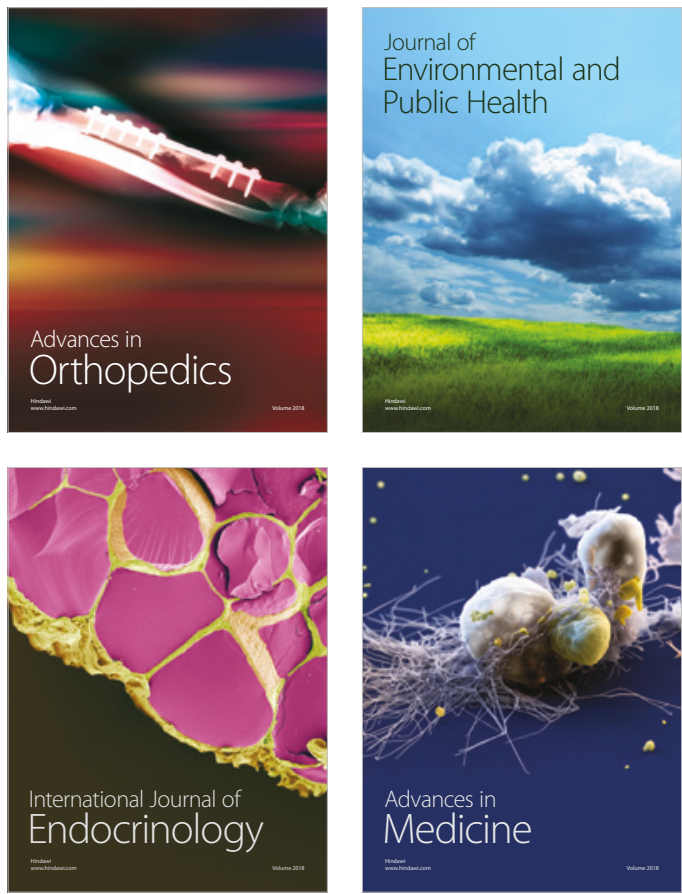
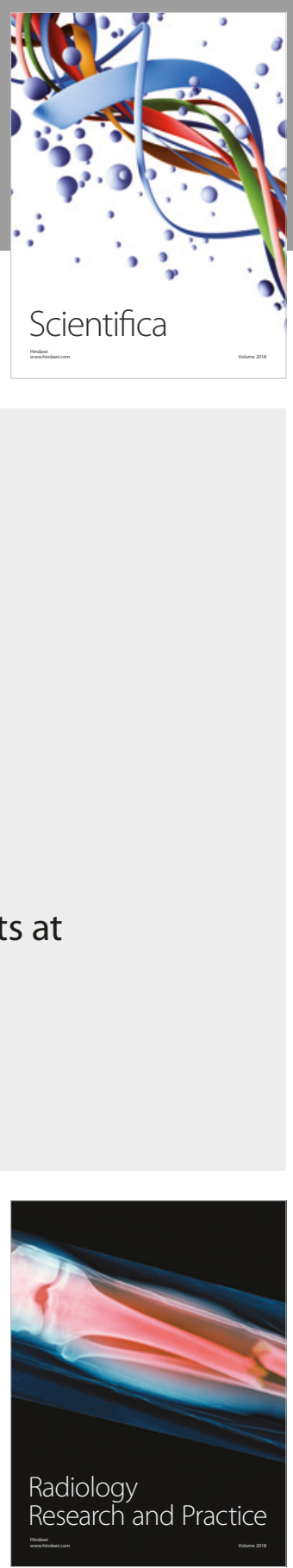

Scientifica

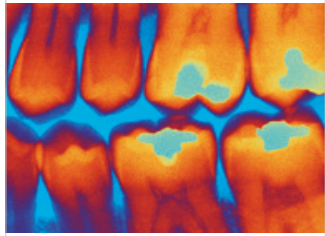

Case Reports in

Dentistry
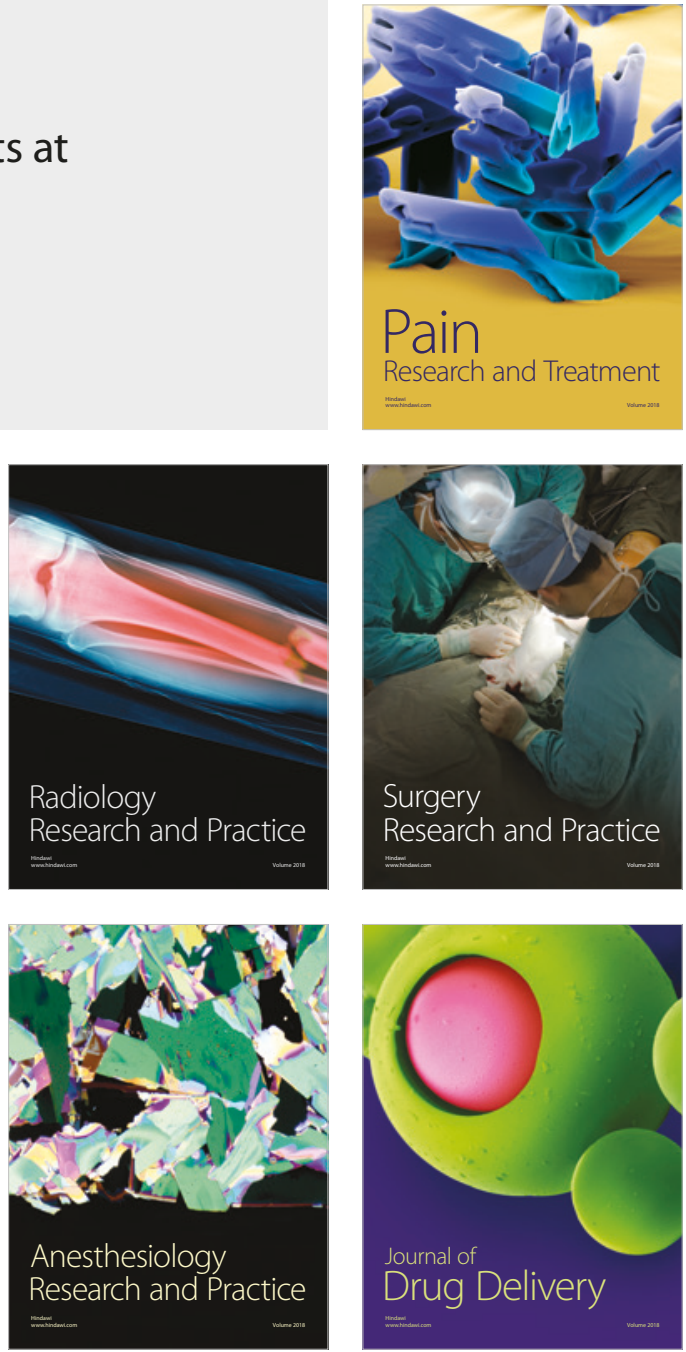